\title{
Genomic imbalances detected through array CGH in fetuses with holoprosencephaly
}

\author{
Isabela Nelly Machado, Juliana Karina Heinrich, Ricardo Barini
}

\begin{abstract}
Objective: Holoprosencephaly (HPE) is heterogeneous in pathogenesis, integrating genetic susceptibility with the influence of environmental factors. Submicroscopic aberrations may contribute to the etiology of HPE. Our aim was to report the molecular analysis of 4 fetuses with HPE and normal metaphase karyotype. Method: A whole genome BAC-array based Comparative Genomic Hybridization (array CGH) was carried out in fetal blood samples. All potential cytogenetic alterations detected on the arrays were matched against the known copy number variations databases. Results: The array CGH analysis showed copy number gains and losses in all cases. We found a recurrent deletion in 15q14 (clone RP11-23J11) and in 15q22 (clone RP11-537k8) in 2 out 4 cases analyzed. We also observed submicroscopic gain in 6p21 in 3 out of 4 fetuses in nearby clones. All these regions were tested in known databases and no copy number variations have been described for them. Conclusion: This is the first report of molecular characterization through a whole genome microarray CGH of fetuses with HPE. Our results may contribute to verify the effectiveness and applicability of the molecular technique of array CGH for prenatal diagnosis purposes, and contributing to the knowledge of the submicroscopic genomic instability characterization of HPE fetuses.
\end{abstract}

Key words: holoprosencephaly, comparative genomic hybridization, prenatal diagnosis, genetic testing, genomic instability.

Instabilidades genômicas detectadas através de array CGH em fetos com holoprosencefalia

\section{RESUMO}

Objetivo: Holoprosencefalia (HPE) é uma malformação heterogênea na patogênese, integrando a suscetibilidade genética com a influência de fatores ambientais. Aberrações submicroscópicas podem contribuir para a etiologia da HPE. Nosso objetivo foi relatar a análise molecular de 4 fetos com HPE e cariótipo normal. Método: Foi realizado um estudo descritivo prospectivo dos achados da técnica de hibridação genômica comparativa baseada em microarranjos utilizando BAC clones de ampla cobertura genômica (BAC-array CGH) em amostras sanguíneas de fetos portadores de holoprosencefalia e com cromossomos numericamente normais ao bandamento G. Todas as potenciais alterações citogenéticas detectadas foram comparadas com bancos de dados com variações do número de cópias conhecidas. Resultados: A análise de array CGH evidenciou ganhos e perdas do número de cópias em todos os 4 casos. Foram encontradas deleções recorrentes em 15q14 (clone RP1123J11) e em 15q22 (clone RP11-537k8) em 2 dos 4 casos analisados. Observou-se em 3 fetos ganho genômico na região 6p21 em clones próximos. Todas estas regiões não apresentaram variações do número de cópias descritas em bancos de dados conhecidos. Conclusão: Este é o primeiro relato de caracterização molecular através de um microarray $\mathrm{CGH}$ de fetos com HPE. Nossos resultados podem contribuir para verificar a eficácia e aplicabilidade da técnica molecular de array CGH para fins de diagnóstico pré-natal, contribuindo para o conhecimento da caracterização de instabilidades genômicas submicroscópicas de fetos com HPE. Palavras-chave: holoprosencefalia, hibridização genômica comparativa, diagnóstico pré-natal, análise genética, instabilidade genômica.

Support
This study was sponsored by
São Paulo State Research Foundation
FAPESP (Grant N N $2007 / 04684-0$ )

Received 25 November 2009

Received in final form 7 July 2010

Accepted 14 July 2010
Cell Culture and Cytogenetics Laboratory, Fetal Medicine Program of the Integral Assistance for Women's Health (CAISM) of the Department of Obstetrics and Gynecology. Faculty of Medical Sciences. State University of Campinas - UNICAMP, Campinas SP, Brazil. 
Holoprosencephaly (HPE) OMIM 2361000, is the most common developmental defect of midline cleavage in human embryonic forebrain, with a variable phenotypic expression. Its estimated prevalence is of 1:16,000 live-births ${ }^{1}$ and 1:250 conceptuses ${ }^{2}$, but it should be higher considering the current advances in neuroimaging that allow the diagnosis of less severe forms of this malformation. The association of holoprosencephaly with other fetal structural and chromosomal abnormalities justifies a detailed investigation of the fetal morphology and karyotype.

Our current understanding of the pathogenesis of HPE attempts to integrate genetic susceptibility with the epigenetic influence of environmental factors. Identifiable genetic causes in humans account for about $15-20 \%$ of all cases $^{3}$. The most common chromosomal abnormality associated to holoprosencephaly is the trisomy 13 . To date, known human mutations in at least 12 different genetic loci have been associated with $\mathrm{HPE}^{4}$, but a very small percentage of all cases has a molecularly defined HPE. Therefore, submicroscopic aberrations may contribute to the etiology of HPE.

The aim of this study was to report the molecular findings through a whole genome array comparative genomic hybridization (array CGH) of 4 fetuses with prenatal ultra-sound diagnosis of HPE in an attempt to improve the knowledge of the submicroscopic abnormalities presented in these malformed fetuses.

\section{METHOD}

\section{Patients and samples}

For this study, fetuses with holoprosencephaly as an isolated brain malformation, no recognized genetic syndrome, and normal metaphase karyotype delivered between January 2008 and July 2009 were prospectively included. This study was carried out after the protocol approval by the institution's ethical committee.

The fetal and parental karyotype analysis was performed using G-banded metaphase chromosomes at approximately the 500 band level. All the parents gave informed consent. The presence and morphologic classification of HPE was confirmed by postnatal MRI (magnetic resonance imaging) or autopsy reports. Maternal diabetes mellitus, drug ingestion, exposure to alcohol and infections were excluded.

Fetal blood samples were collected by cordocentesis at different week's gestation for karyotype, according to the guidelines of the Fetal Medicine Unit of the Women's Hospital of the State University of Campinas (Unicamp).

\section{Molecular study}

Genomic DNA was extracted and purified from fetal blood by means of the Wizard ${ }^{\circ}$ Genomic DNA Purifica- tion Kit (Promega Corp., Madison, WI, USA), according to manufacturer's protocol for whole blood.

Array Comparative Genomic Hybridization was carried out using the Constitutional Chip ${ }^{\circ} 4.0$ (PerkinElmer Inc., Turku, Finland), comprised of approximately 5000 BAC (Bacterial Artificial Chromosome) clones, covering the whole human genome with an average resolution of $<650 \mathrm{~kb}$ and spotted in duplicate.

For each experiment, a sex-mismatched normal reference DNA (Promega Corp., Madison, WI, USA) was used. The DNA concentrations used were $40 \mathrm{ng} / \mu \mathrm{l}$. All experiments included dye reversal and two array hybridizations to obtain an accurate ratio. After post-hybridization washes, slides were scanned, and captured images were analyzed by either the GenePix ${ }^{\circ}$ Pro 6.0 (Molecular Devices Corp.) or the ScanArray Express ${ }^{\circ}$ (Microarray Analysis System 4.0.0.4) software.

After quantification, the cyanine 5 and cyanine 3 average ratio fluorescence intensities for each BAC clone on each of the duplicate arrays (gpr files) were uploaded into the web-based SpectralWare v2.3.3 software (PerkinElmer Inc.), normalized with linear regression algorithms (on a $\log _{2}$ scale) and plotted according to the BAC chromosomal location. The raw data from dye-reversed pairs were combined, and threshold values were ascertained to make inferences according to a clone-by-clone classification procedure to determine the gain, loss and no change status of each clone for each subject, relative to the diploid reference DNA. The threshold values were determined by the software using the "Iterative 2.5X Sigmas" algorithm. Subsequent normalization of the data with "Block Lowess" method was performed for verification of copy number changes. The P values for each probe were also calculated, furnishing additional objective statistical criteria to determine whether deviation of each probe from zero is a significant change ${ }^{5}$. The quality criteria adopted included standard deviation of the intensity ratios among the duplicates less than $10 \%$ and more than $97.5 \%$ of spots with adequate intensity ratio values for analysis ${ }^{6}$. For each analysis, all quality control metrics were noted to be optimal. Clone-by-clone changes were reviewed and only those aberrations detected in both hybridizations were studied further.

All potential cytogenetic alterations detected on the arrays were matched against the known online databases to determine whether they encompassed described copy number variations $(\mathrm{CNV})$ regions.

\section{RESULTS}

Four unrelated fetuses were included in this study. There was no family history of congenital malformations or genetic disorders. Both women and their husbands were healthy, no consanguineous and presented normal 
chromosomes at G-band analysis of peripheral blood. The maternal age ranged from 14 to 36 years old, with a parity varying from zero to two. One woman had previous spontaneous abortions, with no investigation for cytogenetics aberrations. The fetuses' hearts were morphologically normal at the fetal echocardiography. All the four babies were born alive with adequate weight for the gestational age and two of them, the semi-lobar and the alobar cases, died in the same day. An autopsy confirmed the prenatal findings and classification of HPE in all cases. The array CGH analysis showed copy number gains and losses in all cases.

Clinical aspects, the gestation outcome and the total number of clones with genomic instability observed in each case are summarized in Table 1.

We identified recurrent deletion in $15 \mathrm{q} 14$ and in
$15 q 22$ in 2 out 4 cases analyzed. Based on the physical mapping positions as obtained from the March 2006 and February 2009 Assembly of the UCSC Genome Browser (http://genome.ucsc.edu/), the size of the deleted regions were determined to be 40,492 bp $(37,806,124$ $37,846,615)$ and 174,345 bp $(62,082,000-62,256,344)$, respectively. We also observed a recurrent copy number gain in 6p21 region in 3 out of 4 evaluated fetuses involving different but close clones (Figure). The complete list of abnormal clones found in the four fetuses is listed in Table 2. Details about the recurrent abnormal clones are listed in Table 3.

All the identified common regions were tested in known databases and four copy number variations (CNV) were found and excluded. They were gain at 1p36, 2q37.3 and $9 \mathrm{q} 34$, and loss at $5 \mathrm{q} 13$.

Table 1. Clinical aspects, gestation outcome and the total number of clones with genomic instability in 4 fetuses with holoprosencephaly.

\begin{tabular}{|c|c|c|c|c|c|c|c|c|}
\hline Case & Maternal age* & $\mathrm{GPA}^{* *}$ & HPE & $\begin{array}{c}\text { GA of } \\
\text { cordocentesis }\end{array}$ & Karyotype & $\begin{array}{l}\text { Abnormal } \\
\text { clones*** }\end{array}$ & $\begin{array}{c}\text { GA of } \\
\text { delivery }\end{array}$ & Outcome \\
\hline$\# 1$ & 36 & G3 P2 A0 & Lobar & 33 & $46, X X$ & 20 & 36 & Alive \\
\hline$\# 2$ & 14 & G1 P0 A0 & Lobar & 31 & $46, X Y$ & 17 & 39 & Alive \\
\hline$\# 3$ & 28 & G2 P1 A0 & Semi lobar & 31 & $46, X Y$ & 22 & 41 & $\begin{array}{l}\text { Died in } \\
1 \text { hour }\end{array}$ \\
\hline$\# 4$ & 28 & G1 P0 A0 & Alobar & 27 & $46, X Y$ & 05 & 35 & $\begin{array}{l}\text { Died in } \\
10 \text { min. }\end{array}$ \\
\hline
\end{tabular}

GA: gestational age (weeks); *Maternal age (completed years); **G: gravidity, P: parity, A: number of abortions; ***Total number of abnormal clones.

Table 2. Abnormal clones detected in 4 fetuses with holoprosencephaly using whole genome array CGH.

\begin{tabular}{|c|c|c|c|c|c|c|c|}
\hline \multicolumn{2}{|c|}{$\# 1$} & \multicolumn{2}{|c|}{$\# 2$} & \multicolumn{2}{|c|}{$\# 3$} & \multicolumn{2}{|l|}{$\# 4$} \\
\hline G & $\mathrm{L}$ & G & $L$ & G & $L$ & G & $\mathrm{L}$ \\
\hline RP1-283E3 & RP11-328L16 & RP4-628J24 & RP11-23J11 & RP11-625N16 & RP11-91G12 & RP11-353K11 & \\
\hline RP1-160H23 & RP3-375M21 & RP1-77N19 & RP11-537K8 & RP11-118M12 & RP11-352A18 & RP5-1011017 & \\
\hline RP11-602P21 & RP11-173D3 & RP5-856G1 & RP11-300G13 & RP3-462C17 & RP11-551B22 & RP11-15M20 & \\
\hline RP11-48C7 & & RP1-86C11 & & RP11-483F11 & RP11-3G21 & RP1-103M22 & \\
\hline RP1-44H16 & & RP3-428L16 & & GS-261-B16 & RP11-107019 & RP11-80F22 & \\
\hline GS-908-H22 & & RP3-366N23 & & RP11-416K5 & RP11-23J11 & & \\
\hline RP5-908H22 & & RP11-173G21 & & RP11-160E2 & RP11-537K8 & & \\
\hline RP11-598F7 & & RP11-738|14 & & RP11-46E14 & & & \\
\hline RP11-277E18 & & RP11-91H5 & & GS-325-123 & & & \\
\hline RP11-256C2 & & RP11-79M19 & & RP5-860F19 & & & \\
\hline RP11-26M6 & & RP11-14218 & & RP11-379J5 & & & \\
\hline CTD-2184G2 & & RP11-103B5 & & RP4-745C22 & & & \\
\hline RP11-64L12 & & RP11-173D3 & & RP1-14113 & & & \\
\hline RP11-67A5 & & RP1-81F12 & & & & & \\
\hline \multicolumn{8}{|l|}{ RP11-384E6 } \\
\hline \multicolumn{8}{|l|}{ RP11-17I20 } \\
\hline RP1-104C13 & & & & & & & \\
\hline
\end{tabular}

L: Loss; G: Gain. 
Table 3. Recurrent abnormal clones in 4 fetuses with holoprosencephaly.

\begin{tabular}{cccc}
\hline Clone & Chromosome region & Size (bp) & Affected cases \\
\hline RP11-23J11 & $15 q 14$ & 40,492 & $\# 2, \# 3$ \\
RP11-537k8 & $15 q 22$ & 174,345 & $\# 2, \# 3$ \\
RP3-462C17 & $6 p 21.1$ & 118,106 & $\# 3$ \\
RP11-602P21 & $6 p 21.2$ & 224,030 & $\# 1$ \\
RP1-86C11 & $6 p 21.3$ & 89,016 & $\# 2$ \\
\hline
\end{tabular}

bp: base pairs.

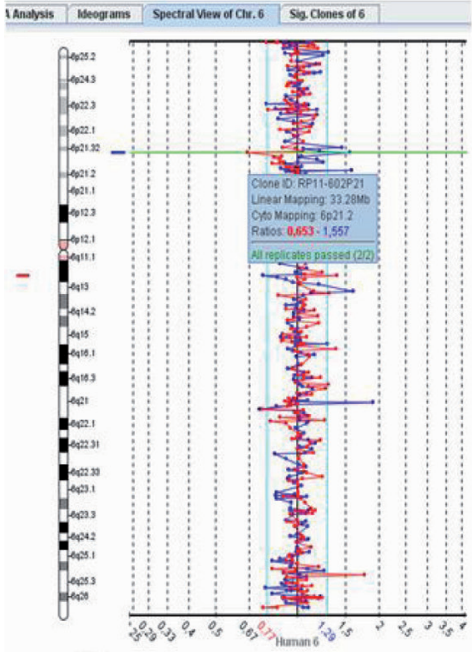

\#1

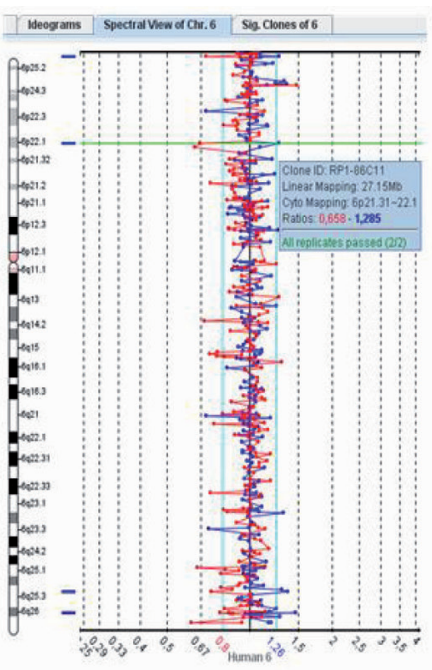

\#2

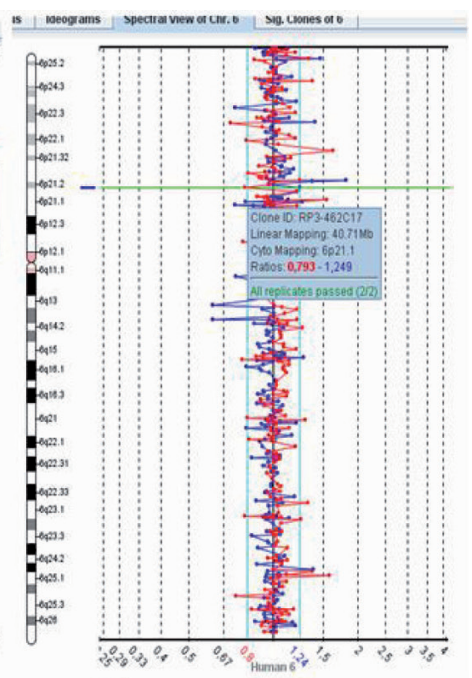

\#3

Figure. Spectral view of chromosome 6 showing recurrent gain at 6p21.

\section{DISCUSSION}

HPE seems to be a multiple hit pathology, requiring two or more events involving several genes and/or environmental factors ${ }^{7}$. The pathology of HPE can be caused by environmental (drugs, infections) and metabolic (diabetes mellitus, alcohol, smoking) factors. Among genetic causes, it can be part of defined malformations syndromes with normal karyotype, chromosomal abnormalities as trisomy 13, trisomy 18 and triploidy, or it can be due to known sequence mutations on described chromosome regions.

The currently identified HPE genes only account for a small portion of all sporadic HPE cases (15-20\%) ${ }^{3}$, and mutations in the currently recognized HPE genes explain only a very small proportion of all sporadic HPE cases ${ }^{8}$. In a cohort of 424 unrelated postnatal cases with severe central nervous system findings, normal karyotype and negative for the for four main HPE genes, micro deletions were found in $4.7 \%$ and no micro deletions were found in 85 individuals with HPE microsigns ${ }^{9}$. The same group of researchers found a percentage of $8.5 \%$ of microdeletions in the prenatal period in 97 fetuses ${ }^{10}$. The remaining cases are assumed to be a non-known etiology manifestation: neither environmental, nor syndromic, nor chromosomal ${ }^{4}$. The difficulties in identifying these genes may relate to the multigenic nature of HPE. Loss of function in a single HPE gene may not lead to the disease. In human, there will be other modifier genes acting in addition $^{11}$. A recent study involving twenty members of an affected family showed the importance of perseverance despite initially negative tests, including applying new technology and testing newly discovered genes and highlighted the fact that genetic disorders may manifest in ways not exactly as traditionally described ${ }^{12}$.

Therefore, we hypothesized that there are still unidentified genes causing underlying submicroscopic aberrations that could contribute to the etiology of HPE. In a first attempt to identify novel candidate regions involved in the pathology of this heterogeneous disease, and to evaluate the feasibility of BAC arrays in the analysis of prenatal samples, we used an array CGH pangenomic approach to report the molecular characterization of group of 4 fetuses with normal karyotype and diagnosis of HPE visible by ultra-sound prenatal care. 
Table 4. Known genes and candidate genes for HPE.

\begin{tabular}{|c|c|c|c|}
\hline \multicolumn{2}{|c|}{ LOCI and known HPE genes } & \multirow{2}{*}{\multicolumn{2}{|c|}{$\begin{array}{c}\text { Candidate genes } \\
\begin{array}{l}\text { Investigated or under } \\
\text { investigation }\end{array}\end{array}$}} \\
\hline 236100 & HPE1 21q22.3 & & \\
\hline 157170 & HPE2 2p21 SIX3 & 600909 & LSS 21q22,3 HPE1 \\
\hline 142945 & HPE3 7q36 SHH & 605194 & CFC1 2q21.1 \\
\hline 142946 & HPE4 18p11.3 TGIF & 181590 & SIL $1 \mathrm{p} 32$ \\
\hline 609637 & HPE5 13q32 ZIC2 & 605189 & DKK1 10q11.2 \\
\hline 605934 & HPE6 2q37.1-q37.3 & \multicolumn{2}{|c|}{ Hypothetical } \\
\hline 601309 & HPE7 9q22.3 PTCH & 602103 & TMEM1 21q22.3 \\
\hline 609408 & HPE8 14q prox & 600288 & FOXA2 20p11 \\
\hline- & HPE9 20p13 & 607502 & DISP1 1q42 \\
\hline- & HPE10 1q42-qter & 609486 & EAPP $14 q 13$ HPE8 \\
\hline- & HPE11 5pter & 609863 & TECT1 12q24.1 \\
\hline- & HPE12 6q26-qter & 603475 & CHRD 3q27 \\
\hline 600725 & gene SHH 7q36 & 602991 & NOG 17q22 \\
\hline 602630 & gene TGIF 18p11.3 & 600073 & LPR2 2q24-q31 \\
\hline 603073 & gene ZIC2 13q32 & 601500 & SMO 7q32.2 \\
\hline 603714 & gene SIX3 2p21 & 606178 & HHIP 4q31.22 \\
\hline 187395 & gene TDGF1 3p23-p21 & 112262 & BMP4 14q22.2 \\
\hline 601309 & gene PTCH 9q22 & 601265 & NODAL 10q22.1 \\
\hline 603621 & gene FOXH1 8q24.3 & 601366 & SMAD2/4 18q21 \\
\hline \multirow[t]{2}{*}{165230} & gene GLI2 2q14 & 608707 & CDO 11q23-q24 \\
\hline & & 605049 & TWSG1 18p11.3 \\
\hline
\end{tabular}

Dubourg et al. ${ }^{4}, 2007$.

The array CGH analysis showed copy number gains and losses in all cases. Interestingly, the alobar case, the more severely affected fetus, presented the smallest number of genomic abnormalities. Indeed, our results did not allow an inkling of correlation between the number and size of these imbalances and the severity of the phenotype.

The current described genes and candidate genes for HPE, with its respective chromosome regions are presented in Table $4^{4}$. It was not a goal of this study to search for mutations in the four main HPE genes ( $\mathrm{HHH}, \mathrm{ZIC} 2$, SIX3, TGIF), but we could observe that there were no abnormal clones in their known loci.

A Medline search using the keywords $15 \mathrm{q} 14$ and holoprosencephaly could not find any citation. The same occurred using the association between $15 \mathrm{q} 22$ or $6 \mathrm{p} 21$ and holoprosencephaly. One patient was related with a de novo reciprocal translocation affecting the breakpoints 6p21.1 and 7q36, presenting premaxillary agenesis (part of the HPE spectrum) as well as skeletal abnormalities and impacted teeth reminiscent of cleidocranial dysplasia (CCD). But, in this patient, the HPE phenotype could be explained by the $7 \mathrm{q} 36$ breakpoint that maps to the sonic hedgehog gene (SHH), the HPE3 described locus ${ }^{13}$. As the mutations in genes mapping the $6 \mathrm{p} 21$ region can cause CCD, the breakpoint in this region in this case appears to explain the CCD phenotype ${ }^{14}$.

A possible association between the $15 \mathrm{q} 22$ region and holoprosencephaly could be postulated considering that, in some instances, the agenesis of corpus callosum can be part of the holoprosencephaly spectrum ${ }^{3}$. Of the clinical manifestations reported cases of individuals with deletions encompassing 15q15-q22 region, one patient showed partial agenesis of corpus callosum ${ }^{15}$ and other showed hypoplastic corpus callosum ${ }^{16}$.

The inheritance background of our findings is unknown as blood samples from the parents were not available for array $\mathrm{CGH}$ analysis to determine if the copy number gains were inherited or de novo.

The greatest care must be taken for molecular prenatal diagnosis in HPE. Even if a mutation has been identified and seems to be transmitted with clinical manifestations in the family, another event, like a mutation in another gene (not yet identified) or an environmental factor, may be necessary to generate the holoprosencephaly phenotype ${ }^{7}$. In this case, molecular biology performed prenatally provides only an additional criterion with regard to prenatal ultrasound or MRI, which still takes precedence over molecular analysis.

Microarray-based CGH is a powerful method to detect and analyze genomic imbalances that are well below the level of detection on high resolution banded karyotype analysis providing a better opportunity for genotype/ phenotype correlations in other similarly affected individuals. Array $\mathrm{CGH}$ is relatively widely used in genetic testing of children. Recently, a case with the middle interhemispheric variant, a milder variant of HPE, was described carrying a deletion of $\sim 10.4 \mathrm{Mb}$ at $6 \mathrm{q} 22.31-\mathrm{q} 23.2$, suggesting a novel candidate gene of $\mathrm{HPE}^{17}$. But its true potential is still under-explored in prenatal diagnosis.

Some advantages of this molecular method is that it does not involve cell culture, does not require prior knowledge of the genomic region involved and the ability to study cases where only DNA is available and no chromosomes can be obtained. The method was reproducible in a clinical standpoint, with reliable results within 48 hours. Thus, we demonstrate that the technique of array CGH can become an excellent tool for prenatal diagnosis. But, it is important to emphasize that array CGH may not replace conventional G-banded karyotype analysis, but it can complement and expand current methods for a precise prenatal diagnosis and syndromes' characterization. One advantage of $\mathrm{G}$ banding analysis is that it allows the detection of somatic chromosomal mosaicism, which has been described in some patients with PHE.

Based on our results, array CGH results are promising in prenatal genetic testing and a study for submicroscopic deletions in fetuses with non-syndromic HPE should be 
considered as part of the routine laboratory evaluation, in addition to high resolution chromosomal and mutation analysis. Positive results in any of these studies will help to better understand the etiology of HPE and aid the establishment of the recurrence risk for family counseling. Moreover, additional research is needed to further establish the role of genes from related chromosome regions in brain development and to determine the prevalence of copy number gain in the $15 q$ and $6 p$ regions among HPE patients. Also, in accordance with others authors, epidemiologic investigations should be conducted to check off environmental factors that could act in coordination with genetic events to give rise to holoprosencephaly.

ACKNOWLEDGMENTS - The authors have no conflict of interest with any of the information presented in this article. We are grateful to the families who participate in this research. We thank members of the Cell Culture and Cytogenetics Laboratory of the Women's Hospital (CAISM - State University of Campinas - UNICAMP) for their contribution throughout the course of this project and Christopher Williams (PerkinElmer Inc., Waltham, MA) for skilled technical assistance. Eletronic-Database and online software: The URL for data presented herein is as follows: SpectralWare ${ }^{\bullet}$ v2.3.3 software (PerkinElmer Inc.), http://service.spectralgenomics.com (for the array analysis). Database of Genomics Variants, http://projects.tcag.ca/variation/ (for CNV search). Copy Number Variation, http://cnv.chop.edu/ (for CNV search). UCSC Genome Browser, http://genome.ucsc.edu/. (for physical mapping positions and size determination of chromosomal regions). Medline, http:// www.ncbi.nlm.nih.gov/pubmed/. (for literature search).

\section{REFERENCES}

1. Rasmussen S, Moore C, Khoury M, Cordero J. Descriptive epidemiology of holoprosencephaly and arhinencephaly in metropolitan Atlanta, 1968-1992. Am J Med Genet 1996:66:320-333.
2. Matsunaga E, Shiota K. Holoprosencephaly in human embryos: epidemiologic studies of 150 cases. Teratology 1977;16:261-272.

3. Cohen MJ. Holoprosencephaly: clinical, anatomic, and molecular dimensions, Birth Defects Res A Clin Mol Teratol 2006;76:658-673.

4. Dubourg C, Bendavid C, Pasquier L, Henry C, Odent S, David V. Holoprosencephaly. Orphanet J Rare Dis 2007;2:8

5. $\quad \mathrm{Ng} \mathrm{G}$, Huang J, Roberts I, Coleman N. Defining ploidy-specific thresholds in array comparative genomic hybridization to improve the sensitivity of detection of single copy alterations in cell lines. J Mol Diagn 2006;8:449-458.

6. Vermeesch J, Melotte C, Froyen G, et al. Molecular karyotyping: array CGH quality criteria for constitutional genetic diagnosis. J Histochem Cytochem 2005:53:413-422.

7. Ming J, Muenke M. Multiple hits during early embryonic development: digenic diseases and holoprosencephaly. Am J Hum Genet 2002;71:1017-1032.

8. Nanni L, Croen L, Lammer E, Muenke M. Holoprosencephaly: molecular study of a California population. Am J Med Genet 2000;90:315-319.

9. Bendavid C, Haddad B, Griffin A, et al. Multicolour FISH and quantitative PCR can detect submicroscopic deletions in holoprosencephaly patients with a normal karyotype. J Med Genet 2006;43:496-500.

10. Bendavid C, Dubourg C, Gicquel I, et al. Molecular evaluation of foetuses with holoprosencephaly shows high incidence of microdeletions in the HPE genes. Hum Genet 2006:119:1-8.

11. Shen J, Walsh C. Targeted disruption of Tgif, the mouse ortholog of a human holoprosencephaly gene, does not result in holoprosencephaly in mice. Mol Cell Biol 2005;25:3639-3647.

12. Solomon $B D$, Lacbawan $F$, Jain $M$, et al.A novel SIX3 mutation segregates with holoprosencephaly in a large family. Am J Med Genet Part A 2009;149: 919-925.

13. Huang J, Hoffman JD, Zhang Y, et al. Identification of a submicroscopic deletion of SHH associated with the holoprosencephaly spectrum by array-based CGH. Clin Genet 2006;69:367-369.

14. Fernandez B, Siegel-Bartelt J, Herbrick J, Teshima I, Scherer S. Holoprosencephaly and cleidocranial dysplasia in a patient due to two position-effect mutations: case report and review of the literature. Clin Genet 2005; 68:349359.

15. Lalani S, Sahoo T, Sanders M, Peters S, Bejjani B. Coarctation of the aorta and mild to moderate developmental delay in a child with a de novo deletion of chromosome 15(q21.1q22.2). BMC Med Genet 2006;7:8.

16. Koivisto P, Koivisto H, Haapala K, Simola K. A de novo deletion of chromosome 15(q15.2q21.2) in a dysmorphic, mentally retarded child with congenital scalp defect. Clin Dysmorphol 1999;8:139-141.

17. Abe Y, Oka A, Mizuguchi M, et al. EYA4, Deleted in a case with middle interhemispheric variant of holoprosencephaly, interacts with SIX3 both physically and functionally. Hum Mutat 2009:30:946-955. 